\title{
Patient Education and Disease Activity: A Study Among Rheumatoid Arthritis Patients
}

\author{
Herman L. M. Brus, Erik Taal, Martin A. F. J. van de Laar, Johannes J. Rasker, \\ and Oene Wiegman
}

Objective. To determine whether patients experiencing high disease activity derive more benefit from patient education than those experiencing low disease activity.

Methods. Data from a randomized study on the effects of a program of patient education were analyzed retrospectively. Four subgroups were studied: the high disease activity subgroup of patients who had participated in the educational program, the complementary low disease activity subgroup, the high disease activity subgroup of controls, and its low disease activity complement. Patients with erythrocyte sedimentation rate $>28 \mathrm{~mm} /$ first hour were classified as having high disease activity. Effects on frequency of physical exercises, endurance exercises, and relaxation exercises and effects on health status (Modified Health Assessment Questionnaire, Dutch Arthritis Impact Measurement Scales [AIMS]) were measured.

Results. There were no significant differences between the adherence parameters of the various pairs of groups. Four months after the educational program

Supported by a grant from the Nationale Commissie Chronisch Zieken (National Committee for the Chronically Ill).

Herman L. M. Brus, MD, and Martin A. F. J. van de Laar, MD, Rheumatologists, Department of Rheumatology, Rheumatology Twente; Erik Taal, PhD, Psychologist, and Oene Wiegman, PhD, Professor of Social Psychology, Department of Psychology, University Twente; and Johannes J. Rasker, MD, Rheumatologist, Department of Rheumatology, Rheumatology Twente, and Professor of Psychosocial Aspects of Rheumatology, Department of Psychology, University Twente, Enschede, The Netherlands.

Address correspondence to Herman L. M. Brus, MD, Medisch Spectrum Twente, Department of Rheumatology, Postbus 50.000, 7500 KA Enschede, The Netherlands.

Submitted for publication October 11, 1996; accepted in revised form May 5, 1997.

(C) 1997 by the American College of Rheumatology. began, anxiety and depression scores on the DutchAIMS had increased among participating patients who were experiencing high disease activity and decreased among those who were experiencing low disease activity.

Conclusions. Patients experiencing high disease activity did not derive more benefit from patient education than those experiencing low disease activity. On the contrary, an increase of anxiety and depression is found in these patients. Further study is needed to confirm our findings.

Key words. Patient education; Rheumatoid arthritis; Disease activity.

\section{INTRODUCTION}

Persons with rheumatoid arthritis (RA) must face many physical, psychological, social, and economic problems (1-8). Beneficial effects of patient education on health behavior and on health status have been found in mixed populations of patients with different forms of rheumatic disease $(9,10)$. Taal et al developed a self-management course for groups, based on the social learning theory of Bandura $(11,12)$ and a similarly based program of Lorig and colleagues $(13,14)$. The results of this course were promising. Beneficial shortterm effects included improved knowledge and selfefficacy expectations about physical functioning, increased adherence to physical exercise therapy and relaxation exercise therapy, increased practice of selfmanagement activities, and an improvement in functional ability. No improvements were found in the frequency with which endurance exercises were performed, nor in pain, depression, or anxiety. After 14 months, there were still beneficial effects on knowl- 
edge, adherence to physical exercise therapy, and selfefficacy expectations about physical functioning (15). Because RA patients with active disease are presumably confronted with more problems than those whose disease is in remission, we performed a retrospective investigation to determine whether level of disease activity was associated with the amount of benefit gained from the educational program. We considered outcomes with regard to adherence to treatment advice and health status.

\section{PATIENTS AND METHODS}

All outpatients between 21 and 65 years old, who had entered the practices of 3 rheumatologists less than 8 years ago and fulfilled the American College of Rheumatology (formerly the American Rheumatism Association) criteria for RA (16) were asked to participate. Informed consent was obtained, and patients were then allocated at random to an experimental or a control group. These groups were subdivided according to the Westergren erythrocyte sedimentation rate (ESR) value into a high disease activity subgroup (ESR $>28 \mathrm{~mm} /$ hour) and a low disease activity subgroup (ESR $\leq 28$ $\mathrm{mm} /$ hour). Other measures for disease activity determined were: C-reactive protein (CRP; mg/liter), hemoglobin (mmol/liter), and a thrombocyte count (number $\times$ $10^{9} /$ liter). All patients continued their current treatments and were referred to physiotherapists for individual treatment and support. The experimental group attended 5 meetings for patient education. The program included: 1) contracting, goal setting, and feedback; 2) self-management and problem-solving; 3 ) information on RA and its treatment, including medication, physical exercise therapy, endurance exercise therapy, relaxation exercise therapy, and pain management; 4) communication skills; 5) coping with depression.

Age, disease duration, functional class according to Steinbrocker et al (17), and adherence to physical, endurance, and relaxation exercise therapies (number of times per week) were ascertained by questionnaire at the beginning of the study. Health status was measured with the Dutch Arthritis Impact Measurement Scales (AIMS) and the Modified Health Assessment Questionnaire (M-HAQ). After 4 months, adherence, DutchAIMS, and M-HAQ were reassessed.

Dutch-AIMS is a Dutch language version of the AIMS health status questionnaire (18-20). We used its 5 series of questions on physical health, the 2 series on psychological health, and the series on pain. The physical health series deal with mobility, physical activities, dexterity, household activities, and activities of daily living. The psychological health series deal with anx- iety and depression. The range of scores for each series is from 0 to 10 , where 0 represents good health and 10 poor health. Overall physical health and psychological health scores are obtained by adding the scores for their constituent dimensions.

The M-HAQ (21) is a short questionnaire that measures physical disability. Its scores range from 1 to 4 , where 1 represents good function and 4 poor function.

Statistics. The initial data of the experimental group had been compared with those of the control group by Taal et al (15). To validate our classification of the patients into subgroups with high and low disease on the basis of ESR, we compared the CRP, the hemoglobin, and the thrombocyte count of the total high ESR group with those of the total low ESR group. In our study we compared the initial scores as well as the changes in the scores after 4 months in 4 pairs of subgroups. The Wilcoxon two sample test was used. Spearman's rank correlation coefficient was computed between disease duration and the psychological health series of the Dutch-AIMS in the total population, as well as between the disease duration and the 4 months' change in these series. The data of patients who withdrew from or dropped out of the study were not included in the analysis.

\section{RESULTS}

One hundred forty patients fulfilled the selection criteria. Seventy-five gave informed consent. Of these, 38 were allocated to the experimental group and 37 to the control group. There were 6 withdrawals from the experimental group and 7 from the control group. ESR was unavailable from 2 patients in the control group. There were no significant differences in age, disease duration, functional class, adherence, or health scores between the experimental and control groups at the beginning of the study (Table 1).

In the total population there were 47 patients classified as having low disease activity, and 13 classified as having high disease activity. Mean values of CRP were 12 (SD 7) and 37 (SD 23) $\mathrm{mg} /$ liter in the respective groups ( $P<$ 0.001), of hemoglobin 8.5 (SD 0.7) and 7.9 (SD 0.9) mmol/ liter $(P<0.05)$, and of the thrombocyte count 265 (SD 55) and 311 (SD 72) $\times 10^{9 / 1 i t e r ~}(P<0.05)$.

The high disease activity subgroup of the experimental group consisted of 7 patients, the low disease activity subgroup of 25 . The high disease activity subgroup of the control group consisted of 6 patients, the low disease activity subgroup of 22 . The only statistically significant difference between complementary subgroups at the beginning of the study was that disease duration was shorter in the low disease activity 
Table 1. Initial patient characteristics, mean (SD)*

\begin{tabular}{|c|c|c|}
\hline & $\begin{array}{c}\text { Experimental } \\
\text { group } \\
(\mathrm{n}=32)\end{array}$ & $\begin{array}{l}\text { Control } \\
\text { group } \\
(\mathrm{n}=28)\end{array}$ \\
\hline Age, years & $50.5(10.4)$ & $49.3(10.9)$ \\
\hline RA duration, years & $3.8(3.6)$ & $4.9(5.1)$ \\
\hline Steinbrocker (1-4)† & $1.9(0.5)$ & $1.8(0.5)$ \\
\hline Physical exercise (times/week) & $1.90(2.81)$ & $3.48(6.60)$ \\
\hline Endurance exercise (times/week) & $7.00(5.76)$ & $8.43(6.46)$ \\
\hline Relaxation exercise (times/week) & $2.62(3.19)$ & $2.79(4.68)$ \\
\hline AIMS Physical $(0-50)+$ & $10.32(6.91)$ & $9.15(5.29)$ \\
\hline AIMS Psychological $(0-20)+$ & $5.76(3.58)$ & $5.86(2.88)$ \\
\hline AIMS Pain $(0-10) \dagger$ & $4.78(2.11)$ & $4.59(1.90)$ \\
\hline M-HAQ (1-4)† & $1.42(0.46)$ & $1.24(0.36)$ \\
\hline
\end{tabular}

subgroup of the experimental group than in the high disease activity subgroup of that group (Table 2).

The changes in the adherence scores of the 2 high disease activity subgroups after 4 weeks were not significantly different from those of their low disease activity complements. Neither were there significant differences between corresponding subgroups of the experimental and control groups in this regard (Table 2).

The score on the psychological dimension of the Dutch-AIMS of the high disease activity subgroup of the experimental group increased, while that of the low disease activity subgroup of the experimental group decreased; the difference between the changes from baseline in these subgroups was statistically significant. The correlation between the disease duration and the psychological dimension of the Dutch-AIMS in the total population at baseline was -0.03 (not significant). The correlation between the disease duration and the change from baseline in the psychological dimension was -0.003 (not significant). There were no statistically significant differences between the high disease activity subgroup of the control group and its low disease activity complement with regard to Dutch-AIMS and M-HAQ, and no statistically significant differences in this regard between the high disease activity subgroup in the experimental group and that in the control group. In the low disease activity subgroup of the experimental group, the M-HAQ score had decreased after 4 months; in the corresponding subgroup of the control group it had increased. This difference is statistically significant (Table 2).

\section{DISCUSSION}

It is conceivable that the effects of group education are not the same for all patients, or that some patients need a different approach than others. We expected patient education to be more beneficial for patients with high disease activity with regard to adherence or health status, but the results of our study did not support this expectation.

There is no consensus about how to measure disease activity (22-25). We chose the ESR for that purpose because it is an inexpensive and easily performed measure. The cut-off point of $28 \mathrm{~mm} /$ first hour is commonly used to help discriminate active disease from less active disease. Other measures for disease activity (CRP, hemoglobin, and thrombocyte count) were different in the high and low disease activity groups, thus indicating the validity of our classification of patients into high and low disease activity groups on basis of the ESR cut-off point of $28 \mathrm{~mm} /$ first hour.

Surprisingly, we found that patients with high disease activity became more anxious and depressed following patient education, while the other patients of the experimental group became less anxious and depressed. There is some concern about the reliability of this finding because of the small samples for the high disease activity experimental group $(n=7)$ and the high disease activity control group $(n=6)$. An additional concern is the difference in disease duration between the high and the low disease activity subgroup in the experimental group. However it is unlikely that this difference in disease duration has biased our results with regard to anxiety and depression, because disease duration did not correlate with the scores on the psychological dimension of the Dutch-AIMS at baseline $(\mathrm{r}=0.03)$, nor with the changes from baseline in the same variable $(r=-0.003)$.

The increase in anxiety and depression following patient education among patients with a high disease activity could be the result of increased awareness of 
Table 2. Initial mean scores and changes after 4 months in the high and low disease activity subgroups of the experimental and control groups, mean (SD)*

\begin{tabular}{|c|c|c|c|c|}
\hline & \multicolumn{2}{|c|}{$\begin{array}{l}\text { Experimental group } \\
\qquad(\mathrm{n}=32)\end{array}$} & \multicolumn{2}{|c|}{$\begin{array}{l}\text { Control group } \\
\quad(n=28)\end{array}$} \\
\hline & $\begin{array}{c}E S R>28 \\
(n=7)\end{array}$ & $\begin{array}{c}E S R \leq 28 \\
(n=25)\end{array}$ & $\begin{array}{c}\mathrm{ESR}>28 \\
(\mathrm{n}=6)\end{array}$ & $\begin{array}{c}\mathrm{ESR} \leq 28 \\
(\mathrm{n}=22)\end{array}$ \\
\hline Age, years & $51.6(9.3)$ & $50.2(10.8)$ & $50.2(11.2)$ & $49.0(11.0)$ \\
\hline RA duration, years & $5.4(2.5) \dagger$ & $3.4(3.8) \uparrow$ & $8.5(10.1)$ & $4.0(2.3)$ \\
\hline Steinbrocker $(1-4) \ddagger$ & $2.14(0.4)$ & $1.8(0.5)$ & $2.2(0.4)$ & $1.7(0.5)$ \\
\hline \multicolumn{5}{|c|}{ Physical exercise (times/week) } \\
\hline Baseline & $2.29(2.36)$ & $1.77(3.00)$ & $1.83(2.56)$ & $3.95(7.35)$ \\
\hline Change $0-4$ months & $1.29(2.69)$ & $1.90(3.06)$ & $1.50(4.37)$ & $-1.95(7.24)$ \\
\hline \multicolumn{5}{|c|}{ Endurance exercise (times/week) } \\
\hline Baseline & $6.83(7.68)$ & $7.06(5.21)$ & $10.00(11.11)$ & $7.94(4.65)$ \\
\hline Change $0-4$ months & $0.00(1.27)$ & $0.76(3.85)$ & $0.60(3.8)$ & $3.63(6.40)$ \\
\hline \multicolumn{5}{|c|}{ Relaxation exercise (times/week) } \\
\hline Baseline & $2.71(3.15)$ & $2.59(3.28)$ & $1.67(1.75)$ & $3.09(5.19)$ \\
\hline Change $0-4$ months & $0.00(1.53)$ & $0.73(2.66)$ & $0.33(1.97)$ & $-0.53(6.18)$ \\
\hline \multicolumn{5}{|l|}{ AIMS Physical $(0-50) \ddagger$} \\
\hline Baseline & $12.75(5.96)$ & $9.64(7.11)$ & $12.23(4.99)$ & $7.73(4.97)$ \\
\hline Change 0-4 months & $1.94(4.68)$ & $-1.32(4.90)$ & $-1.55(4.13)$ & $-0.58(2.10)$ \\
\hline \multicolumn{5}{|c|}{ AIMS Psychological $(0-20) \neq$} \\
\hline Baseline & $5.05(3.88)$ & $5.97(3.55)$ & $6.28(3.83)$ & $5.75(2.66)$ \\
\hline Change $0-4$ months & $1.11(1.50) \S$ & $-1.38(2.34) \S$ & $-0.89(1.64)$ & $-1.00(1.87)$ \\
\hline \multicolumn{5}{|l|}{ AIMS Pain $(0-10) \ddagger$} \\
\hline Baseline & $5.64(1.07)$ & $4.54(2.28)$ & $5.08(2.08)$ & $4.45(1.87)$ \\
\hline Change $0-4$ months & $-0.07(1.20)$ & $-0.30(2.45)$ & $-1.08(2.75)$ & $-0.64(1.92)$ \\
\hline \multicolumn{5}{|l|}{ M-HAQ $(1-4) \ddagger$} \\
\hline Baseline & $1.57(0.45)$ & $1.37(0.46)$ & $1.40(0.39)$ & $1.20(0.35)$ \\
\hline Change 0-4 months & $0.07(0.39)$ & $-0.03(0.31)+$ & $0.26(0.30)$ & $0.04(0.15) t$ \\
\hline
\end{tabular}

the consequences of the high disease activity for functional ability and its association with damage to the joints. The finding that these patients became more anxious and depressed does not appear to support the hypothesis that these are the patients that should benefit most. It is not clear, however, whether it should be taken as a positive or a negative effect. Is it a final outcome or will it be conducive to more effective modes of coping and hence to an improvement in health?

Because treatment with disease-modifying antirheumatic drugs is the only therapy that has been proven to reduce disease activity (26), improving adherence to this treatment should perhaps be included as an important and specific aim of patient education when patients experiencing high disease activity are involved.

The only other difference that we found, that M-HAQ scores improved more in the high disease activity subgroup of the experimental group than in the corresponding subgroup of the control group, is in line with the positive effects of patient education on disability found by Taal et al in their earlier study. Because of the small sample sizes, we may have missed other significant influences of disease activity on the effects of patient education on adherence or health status (Type 2 errors).

Many studies have shown that increases in adherence and improvement of health status can be achieved with patient education $(9,10)$. The results of our study 
suggest that the subgroup of RA patients with high disease activity experienced no additional benefit from patient education when compared to those with low disease activity. Patient education might even evoke anxiety and depression in these patients. Because of small sample sizes for the high disease activity subgroups in our study, no final conclusions can be drawn yet about the differential effects of patient education among RA patients with high disease activity and low disease activity, and further study is needed.

\section{REFERENCES}

1. Meenan RF, Yelin EH, Henke CJ, Curtis DL, Epstein WV: The costs of rheumatoid arthritis: a patient-oriented study of chronic disease costs. Arthritis Rheum 21:827833, 1978

2. Lorig KR, Cox T, Cuevas Y, Kraines RG, Britton MC: Converging and diverging beliefs about arthritis: Caucasian patients, Spanish speaking patients, and physicians. J Rheumatol 11:76-79, 1984

3. Liang $\mathrm{MH}$, Rogers M, Larson M, Eaton HM, Murawaki BJ, Taylor JE, Swafford J, Schur PH: The psychosocial impact of systemic lupus erythematosus and rheumatoid arthritis. Arthritis Rheum 27:13-19, 1984

4. Anderson KO, Bradley LA, Young LD, McDaniel LK, Wise CM: Rheumatoid arthritis: review of psychological factors related to etiology, effects and treatments. Psychol Bull 98:358-387, 1985

5. Cornelissen PJ, Rasker JJ, van Valkenburg JA: The arthritis sufferer and the community: a comparison of arthritis sufferers in rural and urban areas. Ann Rheum Dis 38:51-56, 1988

6. Taal E, Rasker JJ, Seydel ER, Wiegman O: Health status, adherence with health recommendations, self-efficacy and social support in patients with rheumatoid arthritis. Patient Educ Couns 20:63-76, 1993

7. Markenson JA: Worldwide trends in the socioeconomic impact and longterm prognosis of rheumatoid arthritis. Semin Arthritis Rheum 21:4-12, 1991

8. Mitchell JM, Burkhauser RV, Pincus T: The importance of age, education, and comorbidity in the substantial earning losses of individuals with symmetric polyarthritis. Athritis Rheum 31:348-357, 1988

9. Daltroy LH, Liang MH: Athritis education: a review of the literature. Health Educ Q 20:3-16, 1993

10. Hirano PC, Laurent DD, Lorig K: Arthritis patient education studies, 1987-1991: a review of the literature. Patient Educ Couns 24:9-54, 1994

11. Bandura A: The self-system in reciprocal determinism. Am Psychol 133:344-358, 1978

12. Bandura A: Self-efficacy mechanism in physiological activation and health-promoting behavior. In, Adaptation, Learning and Affect. Edited by J Madden, S Matthysse, J Barchas. New York, Raven Press, 1986
13. Lorig K, Lubeck D, Kraines RG, Seleznick M, Holman HR: Outcomes of self-help education for patients with arthritis. Arthritis Rheum 28:680-685, 1985

14. Lorig $\mathrm{K}$, Holman $\mathrm{H}$ : Arthritis self-management studies: a twelve year review. Health Educ Q 20:17-28, 1993

15. Taal E, Riemsma RP, Brus HLM, Seydel ER, Rasker JJ, Wiegman O: Group education for patients with rheumatoid arthritis. Patient Educ Couns 20:177-187, 1993

16. Arnett FC, Edworthy SM, Bloch DA, McShane DJ, Fries JF, Cooper NS, Healey LA, Kaplan SR, Liang MH, Luthra HS, Medsger TA Jr, Mitchell DM, Neustadt DH, Pinals RS, Schaller JG, Sharp JT, Wilder RL, Hunder GG: The American Rheumatism Association 1987 revised criteria for the classification of rheumatoid arthritis. Arthritis Rheum 31:315-324, 1988

17. Steinbrocker O, Traeger CH, Batterman RC: Therapeutic criteria in rheumatoid arthritis. JAMA 140:659-662. 1942

18. Meenan RF, Gertman PM, Mason JH: Measuring health status in arthritis: the Arthritis Impact Measurement Scales. Arthritis Rheum 23:146-152, 1980

19. Meenan RF, Gertman PM, Mason JH, Dunaif R: The Arthritis Impact Measurement Scales: further investigations of a health status measure. Arthritis Rheum 25: 1048-1053, 1982

20. Taal E, Jacobs JW, Seydel ER, Wiegman O, Rasker JJ: Evaluation of the Dutch Arthritis Impact Measurement Scales (Dutch-AIMS) in patients with rheumatoid arthritis. Br J Rheumatol 28:478-491, 1989

21. Pincus T, Callahan LF, Brooks RH, Fuchs HA, Olsen NJ, Kaye JJ: Self-report questionnaire scores in rheumatoid arthritis compared with traditional physical, radiographic and laboratory measures. Ann Intern Med 110: 259-266, 1989

22. Van der Heide A, Jacobs JWG, Dinant HJ, Bijlsma JWJ: The impact of endpoint measures in rheumatoid arthritis clinical trials. Semin Arthritis Rheum 21:287294, 1992

23. Van Leeuwen MA, Heijde DMFM, van Rijswijk MH, Houtman PM, van Riel PLCM, van der Putte LBA, Limburg PC: Interrelationship of outcome measures and process variables in early rheumatoid arthritis: a comparison of radiological damage, physical disability, joint counts, and acute phase reactants. J Rheumatol 21:425429, 1994

24. Van der Heijde DMFM, van 't Hof MA, van Riel PLCM, Leeuwen MA, Rijswijk MH, van der Putte LBA: Validity of single variables and composite indices for measuring disease activity in rheumatoid arthritis. Ann Rheum Dis 51:177-181, 1992

25. Scott DL, Panayi GS, van Riel PLCM, Smolen J, van de Putte LBA, and the Consensus Group of the European Workshop for Rheumatology: Disease activity in rheumatoid arthitis: preliminary report of the Consensus Study Group of the European Workshop for Rheumatology Research. Clin Exp Rheumatol 10:521-525, 1992

26. Cash JM, Klippel JH: Second-line drug therapy for rheumatoid arthritis. N Engl J Med 330:1368-1375, 1994 